TPeriodica Polytechnica Civil Engineering

\author{
62(2), pp. 413-422, 2018 \\ https://doi.org/10.3311/PPci.11334 \\ Creative Commons Attribution (i)
}

RESEARCH ARTICLE

\section{Experimental and Numerical Study of Octagonal Composite Column Subject to Various Loading}

\author{
Mehdi Ebadi Jamkhaneh ${ }^{1}$, Mohammad Ali Kafi ${ }^{1 *}$
}

Received 08 August 2017; Revised 14 November 2017; Accepted 12 December 2017

\begin{abstract}
In this study, experimental tests of the behaviour of steel and partially encased composite (PEC) columns subjected to compressive loading is performed. Evaluation of this type of composite column under axial loading and numerical analysis of its behaviour under combined torsional and axial loading are the main objectives of this study. At first, a parametric study of PEC columns under axial loading was performed in order to find the relationship between flange slenderness ratio of steel column section and concrete confinement. Width-tothickness ratio of the flange, diameter and spacing of the transverse links were considered as variables in this study. It was observed that dimension of transverse links had almost no effect on the capacity of the specimens, however smaller transverse links spacing increased both capacity and deformability of the specimens. The comparison of the code equations given in CSA S16-14 and EN 1994-1-1 revealed that the equation in CSA S16-14 underestimates the capacity. Furthermore, different types of retrofit of cross-shaped steel column including concrete encasement, use of stiffener plates and transverse links were investigated in this research. Results revealed that concrete confinement and use of transverse links had respectively the most and the least effect on increasing torsional capacity of the specimens.
\end{abstract}

\section{Keywords}

partially encased composite column, failure mode, torsional behaviour, compressive capacity, stiffener plate

\footnotetext{
1 Faculty of Civil Engineering, Semnan University, Semnan, Iran

* Corresponding author, email: mkafi@semnan.ac.ir
}

\section{Introduction}

Steel-concrete structures improve the seismic performance of structures and stiffness of high-rise buildings [1]. Taking benefit from composite sections is of high importance in construction and tall buildings industry [2,3]. In recent years, a new type of composite column was introduced that was distinct from the concrete filled tube (CFT) and fully encased composite (FEC) columns, which used the capacity and shape of both types of previous composite columns. Partially encased composite (PEC) column is composed of a thin-walled welded steel H-shaped section; that is infilled with normal-strength concrete. Design rules for PEC columns were developed and then incorporated into the Canadian steel design standard, S16-01 [4] and EN 1994-1-1 [5]. The most important shortcoming in two regulations is the lack of examination and necessary considerations for the behaviour of such columns against torsion loading.

The H-shaped PEC column is made from steel plates having the same thickness that are welded continuously along the web-flange junction. Transverse links are welded to both ends of the flange tips to increase buckling strength and control the outward deformation. This system differs with PEC used in industrial application in the Europe, as the commonly used steel section of such PECs in Europe are of thick hot rolled steel sections which are inherently resistant against buckling. That is why there is no need to use of transverse links for the same, which results in an increase in column weight and lack of fully take benefit from the materials capacity.

In recent years, many investigations conducted experimental and numerical PEC models under concentric and eccentric loads. Hunaiti, Fattah, and Abdel [6] tested a group of PEC columns under eccentric and cyclic loads in their study; they investigated load bearing capacity of columns with transverse links and shear studs. Muise [7] have investigated the connection behaviour of PEC and steel beams to PEC column, respectively. He observed that neither the connection type nor the web thickness affected the performance of the specimen. Chicoine et al. [8] developed a numerical model to investigate effect of concrete confinement as well as residual stresses and 
imperfections in the flanges on the overall column behaviour. Furthermore, the effect of link spacing, flange stiffness, longitudinal and extra transverse reinforcement on the behaviour of PEC columns was studied by Chicoine et al. [9]. Pricket and Driver [10] conducted a series of tests to study the effect of various parameters such as link distance, concrete compressive strength and load eccentricity on the behaviour of these columns. At the end, the force-moment interaction diagram was presented and was further compared with the in test results. Ebadi Jamkhaneh and Kafi [11,12] studied three types of octagonal PEC columns under axial loading as experimental and numerical models. Begum et al. $[13,14]$ presented PECs numerical model using dynamic explicit method under a variety of loading conditions.

Chen et al. [15] conducted the series of experimental and numerical studies on PEC columns subjected to axial and cyclic horizontal loads. They concluded that interval of links effect for preventing local buckling of steel with large width-thickness ratio, and for benefiting the post-buckling capacity of steel. Pereira et al. [16] evaluated the influence of replacing the conventional longitudinal and transverse steel bars on the structural behaviour of PEC columns under concentric loads. Their results show that the effect of the type of reinforcement on the load capacity, stiffness and post-peak behaviour was not significant.

To the best of the authors' knowledge, there are no researches on the torsional behaviour of PEC columns. In all previous works, researchers used PEC columns fabricated with hotrolled H-shaped cross-section or sections with the same thickness of flange and web. In spite of all above mentioned studies, there is a lack of comprehensive investigation on the influence of different thickness of thin-walled and shape of steel section and torsional loading. In the study, different thickness for flanges and webs is used for cross-shaped steel profiles (flange thickness is twice of web thickness) due to the same inertial moments in both directions, symmetry of section, easy implementation, and possible connection in any direction. It should be noted that the proposed column is examined under axial and torsional load. One of the main disadvantages of cross-shaped steel section is its low torsional resistance. To improve the torsional resistance of this type of sections, continuity plates applied in the joint and transverse links are spaced between the flange tips. Generally, in this research, the key objectives of the experimental study are:

- Acquiring better understanding of the effect of key parameters (slenderness ratio of flange, interval spacing of links) on the behaviour of PEC column.

- Proposing a new shape of PEC column and developing an effective and economic procedure to enhance speed erection of structures and investigating the torsional behaviour.

\section{Experimental investigation 2.1 Test description}

Two one-third-scale PEC columns measuring $150 \mathrm{~mm} \times$ $150 \mathrm{~mm} \times 1000 \mathrm{~mm}$ were constructed. Fig. 1 shows typical PEC column geometric parameters. Parameters illustrated in the concrete-side elevation view (Fig. 1(a)) are the column length, L, and the centre-to-centre spacing of the links, s. Parameters illustrated in the plan view (Fig. 1(b)) are the column depth, $d$, the overall flange width, $b_{f}$, the flange thickness, $\mathrm{t}_{\mathrm{f}}$, and the web thickness, $\mathrm{t}_{\mathrm{w}}$. The bare steel section was fabricated from st 37 grade. The nominal plate thickness of flange and web were $6 \mathrm{~mm}$ and $3 \mathrm{~mm}$, respectively. The nominal flange width-to-thickness ratio for the columns was 10 . This value is lower than the maximum flange width-to-thickness ratio of 32 specified by CSA S16-14 [17]. The columns have a constant link spacing equal to $100 \mathrm{~mm}$ and all of the links have a diameter $6 \mathrm{~mm}$. The transverse links are set back from the flange tips so that there is $10 \mathrm{~mm}$ of clear concrete cover between the link and the concrete face, regardless of the link diameter. Columns were cast with normal-strength (nominally $25 \mathrm{MPa}$ ) concrete in the test region. The end zones of the columns (50 $\mathrm{mm}$ of column length at each end) were strengthened by stiffeners to prevent possible failure at these locations due to uneven loading. The main properties of interest during the mix design were strength and workability. Their mix designs are presented in Table 2 . The concrete was made with locally available materials. $12.5 \mathrm{~mm}$ crush coarse aggregate was used. The fine aggregate had a fineness module of 2.4. Considering that the typical concrete density of the mixes was $2300 \mathrm{~kg} / \mathrm{m}^{3}$, the elastic modulus of the normal-strength concrete $(23.715$ $\mathrm{GPa})$ is within typical ranges of American Concrete Institute's (ACI) Manual of Concrete Practice report ACI-318-08 [18]. The average strain at peak stress of the normal strength concrete is $2225 \mu \varepsilon$, which is a typical value. The Poisson's ratio of the normal-strength concrete $(0.13)$ is typical of accepted values ( 0.11 to 0.21$)$ for normal-strength concrete according to the ACI report 318R-92 [19].

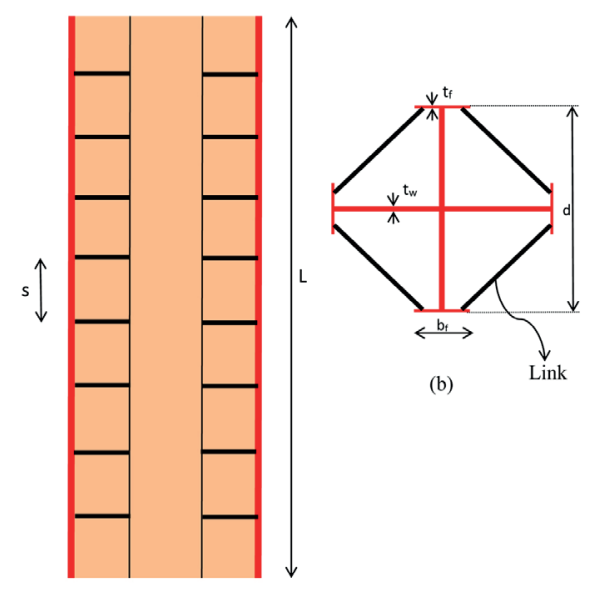

(a)

Fig. 1 Geometry of PEC column in (a) steel-side elevation, and (b) plan 
All coupon tests were conducted in an MTS 1000 universal testing machine, with a tensile capacity of $1000 \mathrm{kN}$, at the Structural Engineering Laboratory of the Semnan University. Load measurements were taken using the internal load cell of the MTS 1000. The stress versus-strain curves generated are typical of hot-rolled structural grade steels. The results of the steel-plate tension coupon tests can be found in Table 2 .

Table 1 Concrete mix design at saturated surface dry conditions

\begin{tabular}{lcccc}
\hline Water & Cement & $\begin{array}{c}\text { Coarse } \\
\text { aggregate }\end{array}$ & $\begin{array}{c}\text { Fine } \\
\text { aggregate }\end{array}$ & W/C ratio \\
\hline 215 & 430 & 1053.2 & 617 & 0.5 \\
\hline
\end{tabular}

All links of a particular diameter were cut from rods of the same heat of steel, as were additional pieces acquired for material testing. Four tension coupons were tested from the steel rods. Two of the coupons were cut from the $6 \mathrm{~mm}$ steel rod used as links. The other two were cut from the $14 \mathrm{~mm}$ steel rod used as longitudinal rebar. The coupons were tested according to ASTM Standard A370 [20] shown in Table 2.

Table 2 Tensile test results for steel plate and steel rod

\begin{tabular}{lcccccc}
\hline & Yield & Ultimate & Elastic \\
& $\begin{array}{c}\text { Stress } \\
(\mathrm{MPa})\end{array}$ & $\begin{array}{c}\text { Stress } \\
(\mathrm{MPa})\end{array}$ & $\begin{array}{c}\text { Yield } \\
(\mathrm{MPa})\end{array}$ & $\begin{array}{c}\text { Strain } \\
(\mu \varepsilon)\end{array}$ & $\begin{array}{c}\text { Hardening } \\
\text { Strain }(\mu \varepsilon)\end{array}$ & $\begin{array}{c}\text { Rupture } \\
\text { Strain } \\
(\mu \varepsilon)\end{array}$ \\
\hline Plate & 257 & 389 & 202100 & 1951 & 16900 & 320000 \\
Rod & 297 & 412 & 195600 & 1568 & 23200 & 451000 \\
\hline
\end{tabular}

\subsection{Test setup}

Two columns were tested at the structural laboratory in Semnan University. The columns were tested with fixed-end condition in one side and vertical slide in another side. Test of the columns under concentric compressive loading was performed using a testing system machine that has a loading capacity of 2 MN. The loadcell applies a compressive force horizontally and has a maximum stroke of $400 \mathrm{~mm}$. The base of the universal testing system (UTS) sits horizontally on a frame. The test setup was similar for each of the two columns tested under concentric axial load. Primary force rate $(5 \mathrm{kN} / \mathrm{min})$ was used to control the UTS. The test began at a force rate of $50 \mathrm{kN} / \mathrm{min}$ until the displacement reached approximately $0.05 \mathrm{~mm}$, during which the electronic data were scrutinized to ensure that all channels were functioning properly. Following this, the force rate was increased to $75 \mathrm{kN} / \mathrm{min}$ until the real-time graphs of the column behaviour indicated that the column stiffness was decreasing (typically about $80 \%$ of the peak load). To minimize dynamic effects, the force rate was then decreased back to $50 \mathrm{kN} / \mathrm{min}$ until failure of the column occurred. If the failure resulted in a sudden drop in column capacity, the force of the UTS was held constant until the measured UTS displacement had stabilized and photographs had been taken. Loading was then changed to displacement control at a stroke rate of $0.06 \mathrm{~mm} / \mathrm{min}$. If the failure resulted in a gradual drop in capacity, the stroke rate was held at $0.06 \mathrm{~mm} /$ min until the column capacity had been reduced to below $85 \%$ of the peak load. Then, the rate was increased to $0.08 \mathrm{~mm} / \mathrm{min}$. Regardless of the failure type, once the degradation of post-peak strength began to slow significantly, defining a reasonably stable residual strength plateau, the stroke rate was increased to $0.1 \mathrm{~mm} /$ min. The column was then unloaded and the unloading behaviour was recorded. Fig. 2 shows the concentric load test setup and the position of linear variable displacement transformers (LVDT). There were five LVDTs (one of them is located in parallel with column axis (no. 1)) that recorded axial and lateral displacements of specimen under compressive loading.

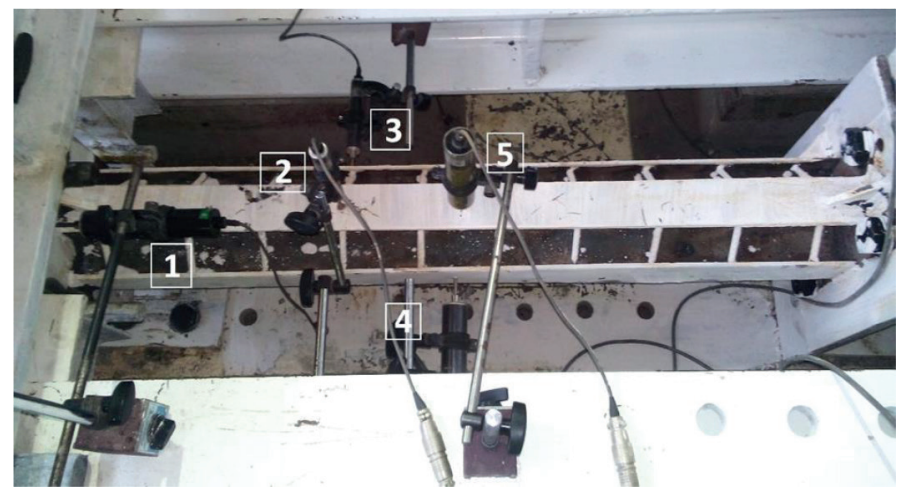

Fig. 2 (a) Position of LVDTs

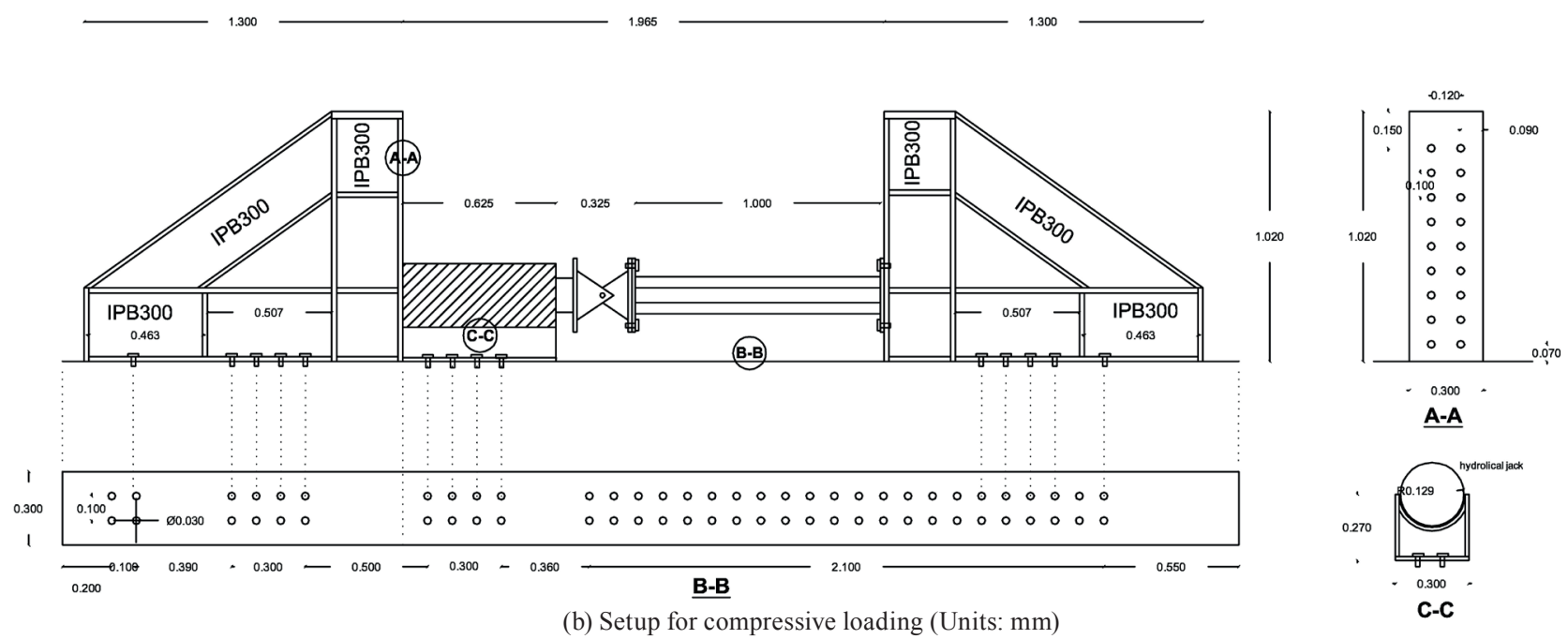

Fig. 2 Setup for concentric compression loading and position of LVDTs. 


\section{Test results and discussion}

\subsection{Load-displacement relationships}

Fig. 3 shows the axial load-displacement responses of the two concentric tested specimens. The values of initial stiffness and maximum load for BS and PEC specimen are $624 \mathrm{kN}, 175$ $\mathrm{kN} / \mathrm{mm}$ and $802 \mathrm{kN}, 217 \mathrm{kN} / \mathrm{mm}$, respectively. The initial stiffness was derived from a linear regression analysis within the elastic range of the load-displacement response. Specimen PEC showed the highest strength, about 1.28 times that of specimens BS. The highest initial stiffness was also seen in specimen PEC, which was $24 \%$ higher than that of specimen BS.

Higher stiffness of PEC column in comparison with BS columns is the result of using concrete and links which leads to more confinement and thus increases the column strength. Additionally, it was observed that presence of concrete in PEC specimens reduces the lateral deflections by 70 percent.

\subsection{Failure modes}

No local buckling of the flanges was observed for PEC column before the peak load was reached. Typically, the failure region was located between adjacent links (Fig. 3).

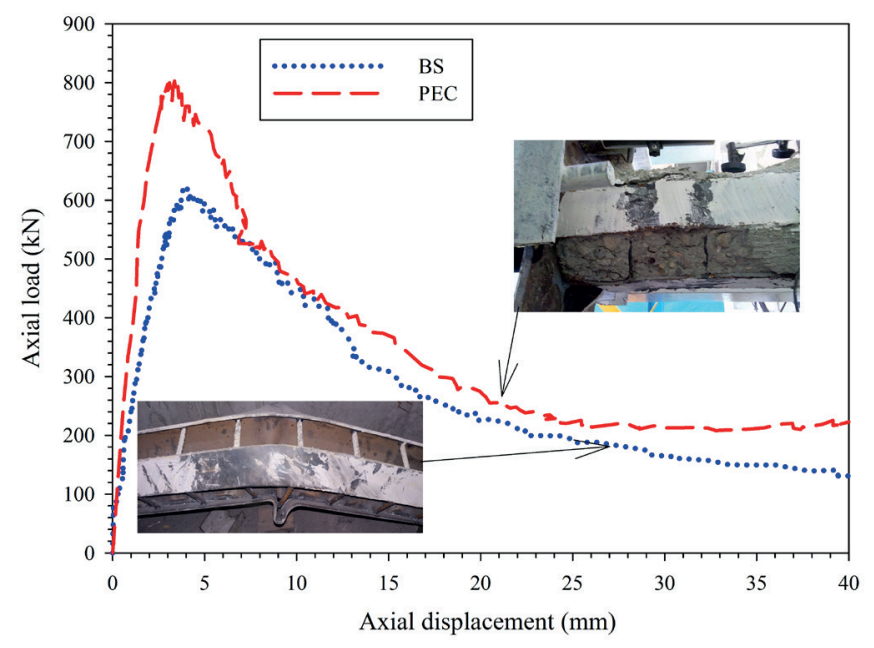

Fig. 3 Axial load-displacement curves of specimens

By removing the crushed concrete after the test, distinct shear-failure planes were exposed. The depths of the shear planes related to the link spacing. For the closest link spacing the shear-failure plane was only as deep as the links themselves. This resulted in small amounts of concrete spalling off of the column. However, for the largest link spacing or fracturing of links (200 $\mathrm{mm})$, the shear-failure plane extended to a point closer to the web than the concrete surface. This resulted in large pieces of concrete exploding out of the column as failure took place. The relationship between the shear-plane depth and the link spacing was expected since the closer link spacing provides a higher degree of confinement to the concrete.

In specimen BS, failure of the column was sudden. After the peak load was reached, local buckling of the flanges in bottom of the column began. In the middle of column, local buckling of the flanges occurred concurrently with the fracturing of the link welds (Fig. 3). During the post-peak loading, a second local buckling began on the web in mid-span. Near the end of the test, flange and web were separated from each other.

\section{Numerical validation and models 4.1 Elements and interaction}

In steel and PEC specimens, all the steel plates are simulated using the four node *Shell element having bending and membrane stiffness terms available from the ABAQUS [21] library. Transverse links are simulated using *BEAM elements in the ABAQUS element library. The beam properties are input by defining the relevant cross-sectional shape from the predefined ABAQUS cross-section library. The 8-node solid elements (C3D8R) were selected to model concrete blocks between the flange plates and the two webs of the PEC section. The transverse links in PEC column were modelled using B31 beam elements, which is a special beam element using linear interpolation and allowing for transverse shear deformation.

In PEC column, first, there is a contact between steel plates and lateral concrete surfaces. Then, when loading starts and continues, flanges of steel sections between two links undergo local buckling which separate flange from concrete block. However, no web local buckling or the separation between web plate and concrete block is observed. Therefore, only one contact algorithm is used for internal surfaces of the flange. A model of mechanical interaction with friction is used as model of contact between steel and concrete surfaces. In ABAQUS, basic Coulomb model of friction was used for formulation of normal and tangential forces using friction coefficient. The value of friction coefficient in the numerical model was considered as 0.1 based on Gorst [22]. The coefficient is the minimum value of coefficient of static friction between steel and concrete surfaces. By using of hard contact, there was no separation between the concrete and steel section until local buckling occurred in the column flanges. Also, to ensure bonding between the concrete and the links, the transverse links are defined as "embedded" reinforcement in the infill concrete blocks, which effectively couples the longitudinal behaviour of the rebar with that of the adjacent concrete.

\subsection{Material behaviour}

A Concrete Damaged Plasticity (CDP) model in ABAQUS is used to simulate the behaviour of concrete. This model is a continuum plasticity-based damage model and assumes tensile cracking and compressive crushing to be the two main failure mechanisms of the concrete material. The compressional and tensile damage parameters are considered as a linear function of inelastic strains. The stress-strain relations under uniaxial tension and compression are taken into account in Equations (1) and (2). 


$$
\begin{aligned}
& \sigma_{t}=\left(1-d_{t}\right) \cdot E_{0} \cdot\left(\varepsilon_{t}-\varepsilon_{t}^{\sim p l}\right) \\
& \sigma_{c}=\left(1-d_{c}\right) \cdot E_{0} \cdot\left(\varepsilon_{c}-\varepsilon_{c}^{\sim p l}\right)
\end{aligned}
$$

Where $\sigma_{t}$ is tensile stress, $\sigma_{c}$ is compressive strength, $E_{0}$ is elastic modulus of concrete, $d_{t}$ and $d_{c}$ are tensile and compressive damage of concrete and $\varepsilon_{t}$ and $\varepsilon_{c}$ are tensile and compressive strain of concrete, respectively.

Tension stiffening also allows to model strain-softening behaviour for cracked concrete. Thus it is necessary to define tension stiffening in CDP model. ABAQUS allows us to specify tension stiffening by post failure stress-strain relation or by applying a fracture energy cracking criterion [21]. There is a mesh sensitivity problem when cracking failure in not distributed evenly. To overcome this unreasonable mesh sensitivity problem Hillerborg's [23] fracture energy approach can be used instead of post failure stress-strain relation. The amount of energy $\left(G_{F}\right)$ which is required to open a unit area of crack is assumed as a material property. Thus; concrete's brittle behaviour is defined by stress-displacement response rather than a stress-strain response. Specifying the post failure stress versus corresponding cracking displacement is enough to describe this approach. For tensile behaviour of concrete, bilinear model is adopted as plotted in Fig. 4 [24]. Crack opening $\left(w_{c}\right)$ is calculated as a ratio of the total external energy supply $\left(G_{F}\right)$ per unit area required to create, propagate and fully break a model crack in concrete. However; model tensile fracture energy of concrete is defined as a function of the concrete compressive strength, $f_{c}^{*}$, in CEB-FIP MC90 [25] as shown in Equation (3). In this equation $G_{f o}$ is a coefficient related to the maximum aggregate size $\left(d_{\max }\right)$ [26].

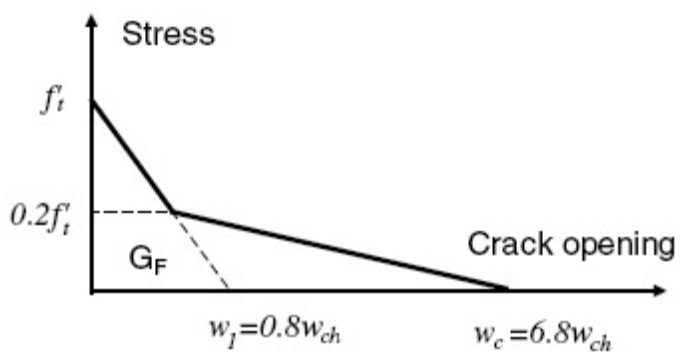

Fig. 4 Bilinear tensile behaviour [24]

$$
G_{F}=G_{f 0}\left(\frac{f_{c}^{*}}{10}\right)^{0.7}
$$

The model proposed by Hsu and Hsu [27] was used to determine the compressive stress-strain ratio of the concrete. This model may be used for concrete with maximum compressive strength of $62 \mathrm{MPa}$. This model calculates compressive stress values from on the ascending part to on the descending part. In this model, compressive stress is found through Equations (4) and (5).

$$
\begin{aligned}
\sigma_{c}=\left(\frac{\beta\left(\frac{\varepsilon_{c}}{\varepsilon_{0}}\right)}{\beta-1+\left(\frac{\varepsilon_{c}}{\varepsilon_{0}}\right)^{\beta}}\right) \sigma_{c u} \\
\beta=\frac{1}{1-\left[\frac{\sigma_{c u}}{\varepsilon_{0} E_{0}}\right]} \\
\varepsilon_{0}=8.9 \times 10^{-5} \sigma_{c u}+2.114 \times 10^{-3}
\end{aligned}
$$

In this study, Nayal and Rashid's model [28] was used to plot the stress-strain relationship at the tension area. In order to prevent runtime error, there is a decrease from ultimate stress $\sigma_{t}$ to $0.8 \sigma_{t}$ in ABAQUS software. Equation (6) be used to find maximum tensile stress.

$$
\sigma_{t}=0.3\left(\sigma_{c}\right)^{\frac{2}{3}}
$$

The nonlinear behaviour of steel elements is simulated using an isotropic hardening model based on the von Mises yield criterion.

\subsection{Finite element verification}

In this section, to assess the capability of the developed numerical model in simulating the PEC and steel columns, the results of the experimental tests are employed to verify and calibrate the developed numerical model in ABAQUS. In simulation of loading condition, a given displacement control is imposed. Fig. 5 shows the comparison of numerical simulation with the test results. Considering comparing the charts in two linear and non-linear areas, it shows a good agreement in the initial elastic stiffness and slope of the second part of the curve. It can be concluded that the FE model and material constitutive adopted in this paper are reasonable. Analyses were executed to validate the performance to local buckling under compressive stress of shell elements used for the steel and the axial capacity of concrete brick elements used for the concrete.

\section{Parametric investigation on PEC column under axial loading \\ 5.1 Link spacing}

The distance between links defined as a free distance significantly affects the columns behavior. The local buckling of the suggested section results in a decrease in capacity and formability of such type of columns; considering results it may be suggested that the links interval distance with $50 \mathrm{~mm}$ intervals the failure has a more gradual trend in comparison to $100 \mathrm{~mm}$ intervals. In Fig. 6, such trend has been indicated in force-displacement curve for PEC-CL column with a variety of links intervals. The closer interval has the better loading capacity and deformability. The long interval space between the links due to the link broken weld results in formation of deep shearing cracks and 


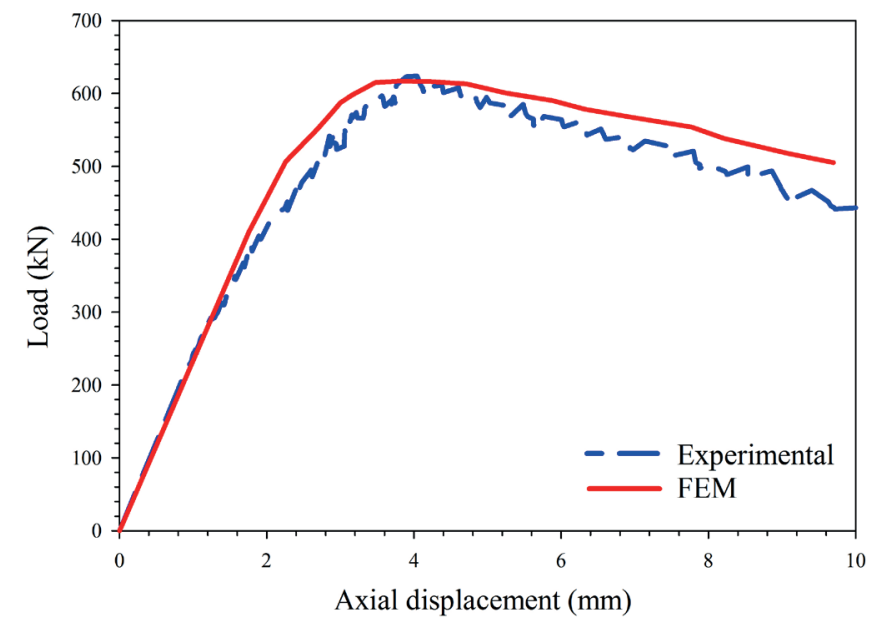

(a)

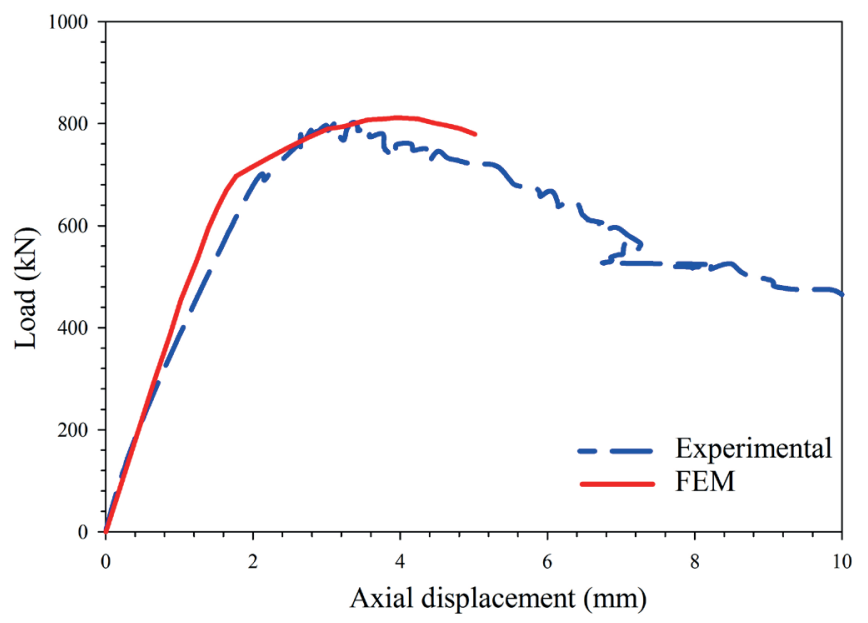

(b)

Fig. 5 Comparison of load-displacement curve between FEM and experimental results of (a) Bare steel and (b) PEC column under compressive loading.

decreased loading bearing capacity. The broken welds or links in turn causes a decrease in concrete confinement effect which automatically reduces column load bearing capacity as well. This issue is observed in using $200 \mathrm{~mm}$ intervals among the links in comparison to the shorter intervals.

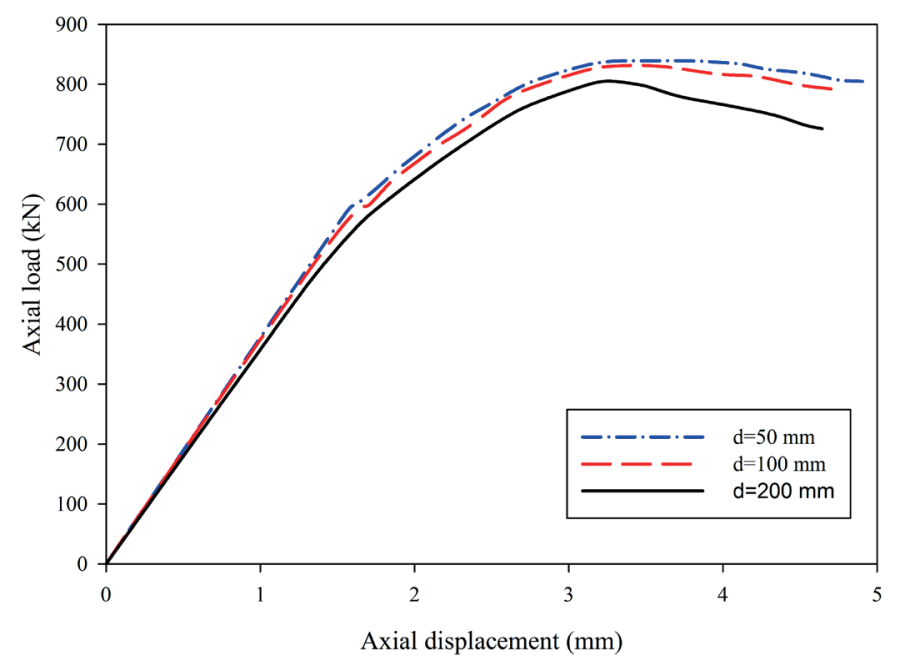

Fig. 6 Comparison of transverse link intervals in specimen PEC

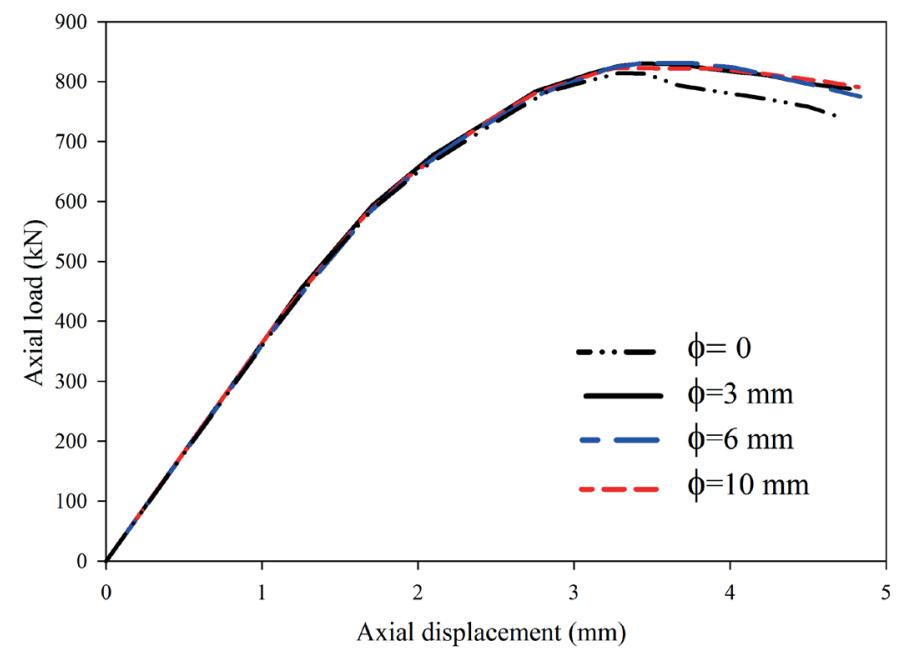

Fig. 7 Comparison of load-displacement relationships of diameter transverse links of specimen PEC

\subsection{Diameter of transverse links}

Fig. 7 shows the effect of different diameter on the behaviour of columns. Lack of transverse link has resulted in early loss in column load-bearing capacity, which emanates from early buckling of the relevant steel beam flanges. However, no significant changes have been observed in column load-bearing capacity. Therefore, it may be expressed that the effect of link presence/non-presence is far more significant than that of transverse link diameter.

\subsection{Width-thickness (slenderness) ratio of flange}

This section describes the limiting slenderness ratios compression flanges. The slenderness ratio for flanges is denoted Ratio, and is equal to 5, 10, 20, and 30 for column PEC. These values are lower than the maximum flange width-to-thickness ratio of 32 specified by CSA S16-14. Fig. 8 depicts the behaviour of column PEC with different Ratio.

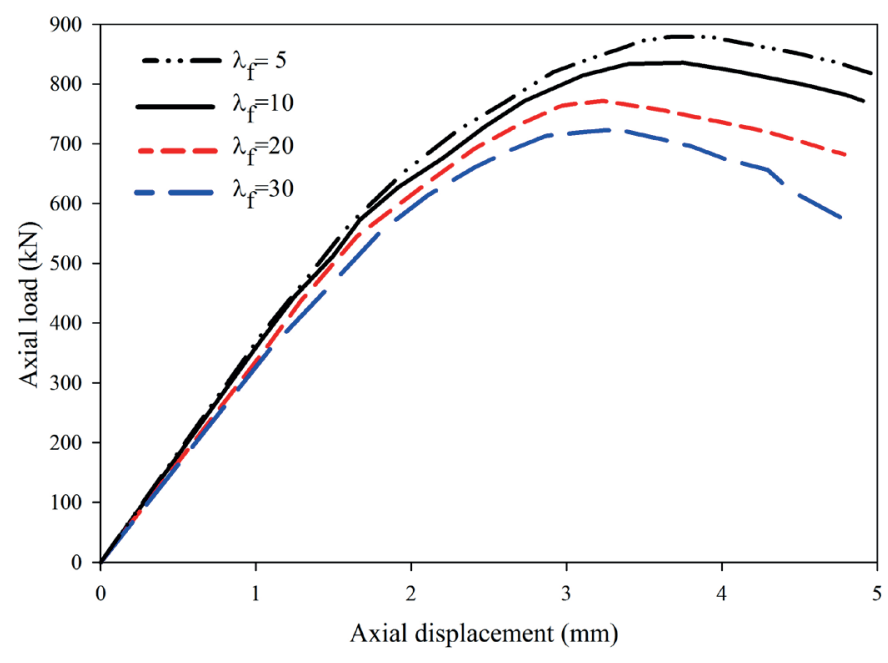

Fig. 8 Comparison of width-thickness ratio of flange of specimen PEC

According to numerical results of non-linear static analyses, columns with bigger flange width-to-thickness ratios experience less strength in comparison to column with bigger 
flange thickness. Meanwhile, sudden strength loss is seen in columns with bigger width-to-thickness ratios after load peak. Such big flange width-to-thickness ratio results in commencement of early non-linear behaviour in comparison to smaller ratio state. The load-bearing capacity is decreased roughly $52 \%$ by increasing the flange width-to-thickness ratio from 5 to 30 . On the other hand, it is observed that by decreasing such ratio the maximum load resulted deflection is also decreased accordingly, which is due to flange premature buckling.

When octagonal PEC columns reach their ultimate strength, the average ratio of the axial compressive load to the yield load of steel tube is equal roughly one. The validated FE model is further used for parametric study to understand the effect of flange width-to-thickness ratio on the mechanical performance of octagonal PEC columns.

The ultimate bearing capacity $\left(N_{u}\right)$ of axially-loaded octagonal PEC columns can therefore be illustrated as:

$$
\begin{gathered}
N_{u}=A_{s} f_{y}+A_{r} f_{r}+\chi A_{c} f_{c} ;(0 \leq \chi \leq 1.8) \\
\chi=-0.62+\frac{1049504.6}{\left(\frac{\frac{b_{f}}{t_{f}}}{4.22 \times 10^{-8}}\right)^{0.7}}
\end{gathered}
$$

The predicted column load was computed using Equations (8) (for CSA S16-14) and (9) (for EN 1994-1-1).

$$
\begin{gathered}
C_{r c}=\left(\phi A_{s e} F_{y}+0.95 \alpha_{1} \phi_{c} A_{c} f_{c}^{\prime}+\phi_{r} A_{r} F_{y r}\right)\left(1+\lambda^{2 n}\right)^{1 / n} \\
N_{p l, R d}=A_{a} f_{y d}+A_{s} f_{s d}+0.85 A_{c} f_{c d}
\end{gathered}
$$

$N_{p l, R d}=C_{r c}=$ The factored compressive resistance, $\phi=0.90$ (Resistance factor of structural steel), $\phi_{c}=0.65$ (Resistance factor of concrete), $\phi_{r}=0.85$ (Resistance factor of reinforcing steel bars), $A_{s e}=$ Effective steel area of the steel section, $A_{c}$ = Area of concrete, $A_{r}=$ Area of longitudinal reinforcement, $f_{s d}=F_{y}=$ Yield strength of steel plate, $f_{c d}=f_{c}^{\prime}=$ Compressive strength of concrete, $f_{y d}=F_{y r}=$ Yield strength of steel bar, $\lambda=$ Slenderness parameter, $\alpha=0.85-0.0015 f_{c}^{\prime}$ (but not less than 0.73 ), and $n=1.34$.

According to the Equations (8) and (9), compressive capacity of PEC column is $688 \mathrm{kN}$ and $876 \mathrm{kN}$ for CSA S16-14 and EN1994 design equations, respectively. The PEC column has the highest test-to-predicted load corresponding to the CSA S16-14 equation ratios, 1.17. CSA S16-14 design calculations reduce the capacity of the steel flanges to account for their susceptibly to local buckling between the links. Eurocode formula has a consistent factor $(0.85)$ for all confinement condition in PEC specimens that is conservative.

\section{Torsional behaviour of PEC column and strengthening methods for cross-shaped steel column}

One of the subjects least studied in current codes regarding composite columns is behaviour of this column under torsion and methods of improvement its behaviour. Due to few investigations in this field, in this section a cross-shaped steel column and an octagonal PEC column were investigated under constant gravity load and varying monotonic torsional loading. Each column was tested in accordance with three cases illustrated in Fig. 9. The second and third cases are used to find a way of enhancing torsional capacity of the PEC columns. Description of the tested models are given in Table 3.

Stiffening plates used at top and bottom of the column have a length of $150 \mathrm{~mm}$ and a thickness same as that of the column flange $(6 \mathrm{~mm})$. Diameter and spacing of the transverse links are similar to those of the tested specimens. Results of these tests are given in the form of torsional moment- rotation diagram, formation and propagation of plastic hinge and strain along the column.

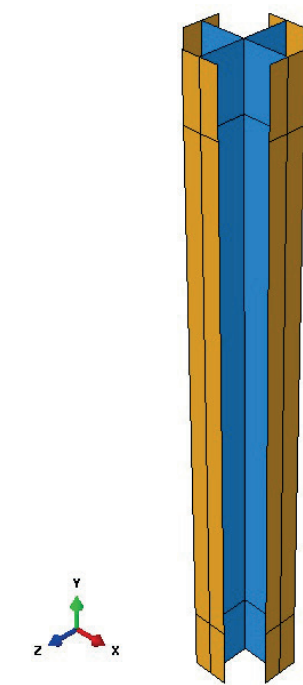

(a)

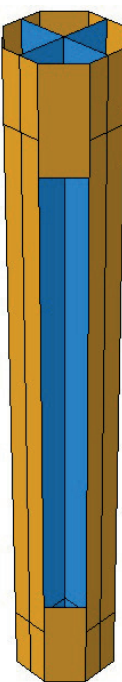

(b)

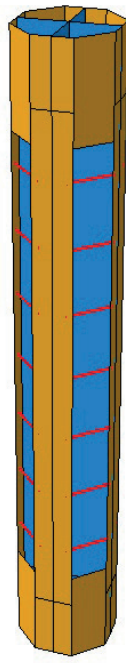

(c)
Fig. 9 Three types of cross-shaped column under torsion load

Table 3 Description of specimens

\begin{tabular}{lc}
\hline Description & Specimen \\
\hline Bare Steel column & BS \\
$\begin{array}{l}\text { Bare steel column strengthened with two stiffener at top } \\
\text { and bottom of the column }\end{array}$ & BS-St \\
$\begin{array}{l}\text { Bare steel column strengthened with two stiffener at top } \\
\text { and bottom of the column and using of transverse links }\end{array}$ & BS-St-L \\
$\begin{array}{l}\text { Partially Encased Composite column } \\
\text { PEC column strengthened with Stiffeners at the top and } \\
\text { bottom of the column }\end{array}$ & PEC \\
$\begin{array}{l}\text { PEC column strengthened with Stiffeners at the top and } \\
\text { bottom of the column and using of transverse links }\end{array}$ & PEC-St-L \\
\hline
\end{tabular}




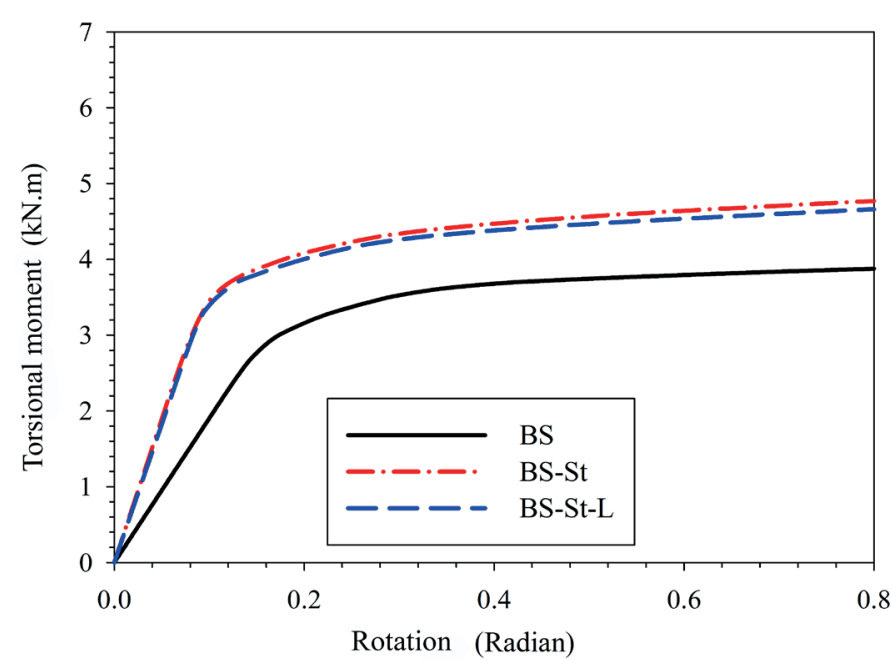

(a)

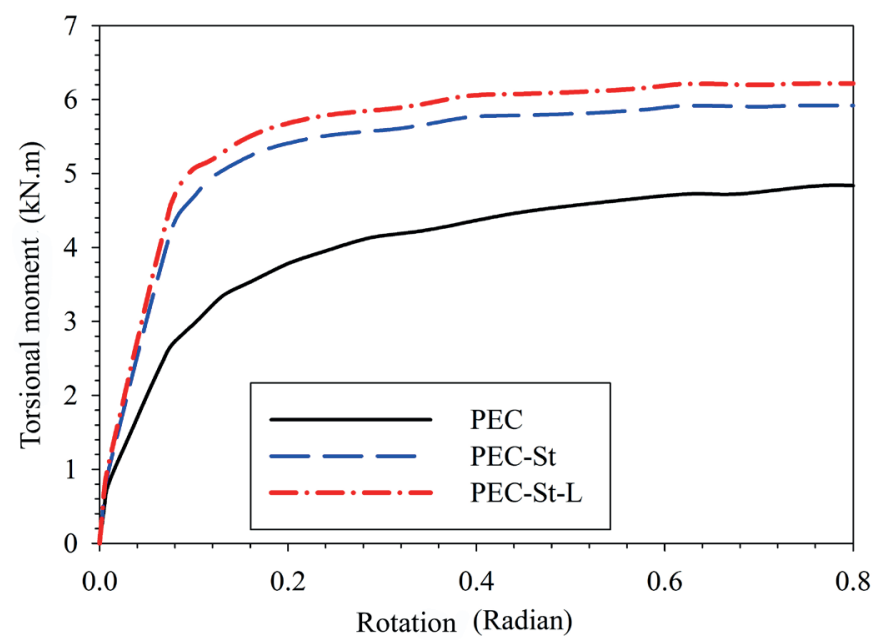

(b)

Fig. 10 Torsional moment-rotation curve, (a) bare steel column, (b) PEC column

\subsection{Moment-rotation relationship}

In this section, a $100 \mathrm{kN}$ constant force combined with linear incremental torsional moment is applied on top of the column. A rigid beam on top of each specimen is used to apply torque. Fig. 10 illustrates results of two series of the specimens.

In bare steel columns, most of the torsional moment is withstood by the four flanges and column webs have less effect in this regard; this is the result of less torsional stiffness of the column web due to being a thin-walled open section. BS specimen has the least rotational stiffness amongst bare steel sections however its rotational stiffness can be increased up to $91 \%$ by adding two hardening plates at top and bottom of the column. This is the result of an increase in polar moment of inertia on top and bottom of the section which sustain most of the torsional moment and rotation. By adding transverse links to BS-St column and creating BS-St-L column, torsional stiffness would increase only by an amount of 3\%. Maximum torsional moment resisted by BS-St-L specimen is $4.9 \mathrm{kN} . \mathrm{m}$ almost equal to that of BS-St specimen but $20 \%$ more than that of BS specimen.

In PEC columns, it was observed that PEC-St-L specimens have the highest torsional rigidity and resistance as expected. In comparison between PEC and PEC-St-L Specimens, an increase of $50 \%$ and $27 \%$ was observed in torsional stiffness and torsional moment of resistance respectively. Fig. 10(b) shows that the first section of the diagram has two initial stiffness; this reduction in stiffness is the result of tensile and shear cracking in the middle of the concrete and propagation of the damage along the concrete portion of the section. This reduction continues to the extent that most of the middle concrete portion of the column is damaged and torsional moment is solely sustained by steel section of the column.

A comparison described below is made in order to better understand the effects of concrete, hardening plates and transverse links. By adding hardening plate to the BS column, rotational stiffness is increased by an amount of $91 \%$. By adding concrete to the BS column, this increase of rotational stiffness would be only an amount of 5\%. Effects of using concrete confinement will increase torsional stiffness and resistance greatly. By using hardening plates in PEC columns, torsion stiffness is increased by $40 \%$. Amongst these methods, use of concrete and hardening plates improve torsional properties greatly.

\subsection{Effect of compressive load ratio on torsional capacity}

Both groups of BS and PEC columns were tested under torsional moment combined with three constant compressive force ratio (ratio of applied compressive force to yield compressive force of the section) of $10 \%$ to $80 \%$. Fig. 11 shows variation of torsional stiffness in relation with different compressive force ratios. It is observed that variation of compressive force ratio has almost no effect on torsional behaviour of specimens in BS column until 30\% load ratio. Although in PEC columns compared to BS columns we observe more effects on torsional behaviour, yet these effects are almost negligible before $30 \%$ load ratio.

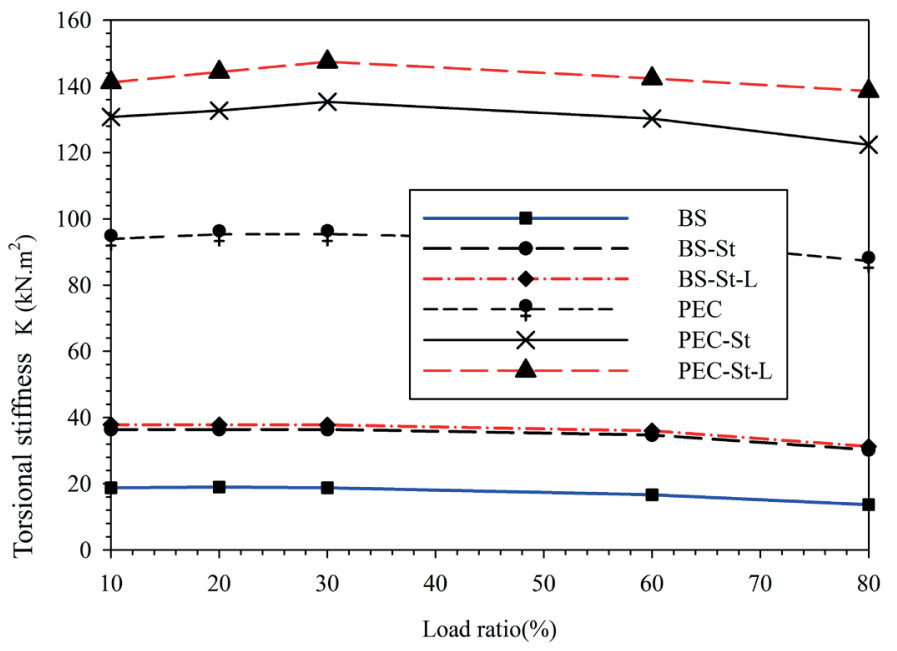

Fig. 11 Load ratio- torsional stiffness of specimens 


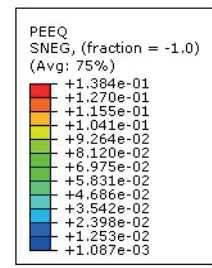

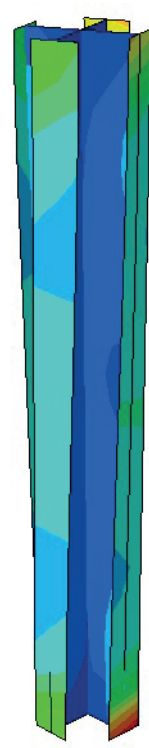

(a) BS

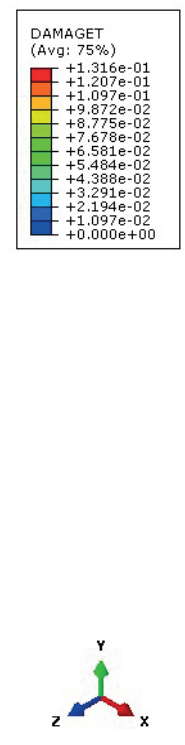

Fig. 12 Failure mode of two specimens

\subsection{Failure and fracture mechanism}

Fig. 12 shows failure and fracture modes for both steel column and PEC column. In BS columns, maximum torsional rotation and torsional moment is sustained at the point of load application and at the column support, therefore these locations reach to the ultimate plastic strain of steel material prior to other locations. Use of hardening plates in BS-St specimen delays formation of plastic hinge and enhances torsional stiffness of the specimen which leads to shifting of plastic region to a level beneath the hardening plates in column flanges. Moreover, it was observed that use of transverse links has little effect on changing or shifting yield mechanism. In this regard, none of the transverse links reached to their yield strain which demonstrates that these links are incapable of having any effect on delaying or changing column rupture mode.

Use of specimens confined with concrete (PEC) causes a change in force transmission and yielding of column. Due to high stiffness of concrete, at first middle portion of the concrete is damaged due to tensile and shear stresses caused by applying torsional moment which gradually this damage is propagated toward the height of the column. After total rupture of the middle concrete portion of the column, torsional moment would be solely sustained by web and flange plates of the column. In other words, steel portion of the column would stay perfectly in linear elastic state prior to failure of most of middle concrete portion of the column.

\section{Conclusions}

Experimental and numerical research project were undertaken to assess the behaviour of octagonal PEC cross-shaped columns made under axial and torsional loading. A total of two (BS and PEC) columns were tested. Relevant finite element analysis was also undertaken. The failure modes, load-displacement responses, column strength and rotation capacity were discussed. The following conclusions could be drawn from this study:

1. With strengthening of the BS column by concrete, the axial compressive strength of the column increased by $34 \%$ and the lateral deflection decreased by $70 \%$. The failure mode was changed from global buckling to local buckling at the top pf the PEC column.

2. A finite element model was proposed for comparison with the experimental specimen, which had acceptable adaptation in elastic stiffness and post-peak load behaviour. After validation process, parametric studies were performed on the PEC column specimen. The important key parameters in this study were the distance between the links, the diameter of the transverse link and the width to thickness ratio of the flange.

3. The compressive capacity decreases with increasing the distance between the transverse links. This is due to the formation of shear cracks in concrete. Additionally, no appreciable change in bearing capacity was observed with changing link diameter. But the removing of transverse links led to a significant reduction in axial compressive capacity. This is due to the lack of control of the local buckling of the flange plate. Also, the compressive capacity is reduced to $52 \%$, when the slenderness of column flange changed from 5 to 30 .

4. An analytical equation was presented to consider the effect of flange slenderness on the compressive capacity of the PEC columns. The effect of this parameter is considered on the coefficient of concrete confinement. The range of this coefficient is from zero to 1.8 , which value of 1.8 related to complete confinement and creates conditions as the CFT column.

5. By comparing test values with the equations between two codes, CSA S16-14 and EN 1994-1-1, it is clear that the value obtained in the CSA S16-14 is conservative. This is due to the fact that the equation in the CSA S16-14 incorporates the effect of the flange buckling with correction in the effective area of the flange.

6. The behaviour of both columns was assessed under the torsional load and simultaneously the constant gravity load. Two methods were investigated by using the transverse plates at the top and bottom of the column and using transverse links to improve their behaviour. Among of different cases, the use of concrete and the link had the most and least effect on the torsional strength.

7. Generally, the torsional stiffness of the columns decreases by increasing the load ratio. Specially in the load ratio greater than $50 \%$, the torsional stiffness of decreasing rate has a faster trend. It is noted that with increasing load ratio up to $30 \%$ in the PEC columns, torsional stiffness is a relatively upward trend. This is due to the effect of compressive strength on delaying the cracking of concrete. After this load ratio, the torsional stiffness experiences a downward trend. 


\section{References}

[1] Ahmadi, M., Naderpour, H., Kheyroddin, A. "Utilization of artificial neural networks to prediction of the capacity of CCFT short columns subject to short term axial load". Archives of Civil and Mechanical Engineering, 14(3), pp. 510-517. 2014. https://doi.org/10.1016/j.acme.2014.01.006

[2] Ahmadi, M., Naderpour, H., Kheyroddin, A., Gandomi, A. H. "Seismic Failure Probability and Vulnerability Assessment of Steel-Concrete Composite Structures". Periodica Polytechnica Civil Engineering, 61(4), pp. 939-950. 2017. https://doi.org/10.3311/PPci.10548

[3] Ahmadi, M., Naderpour, H., Kheyroddin, A. "ANN Model for Predicting the Compressive Strength of Circular Steel-Confined Concrete". International Journal of Civil Engineering, 15(2), pp. 213-221. 2017. https://doi. org/10.1007/s40999-016-0096-0

[4] CSA S16-01. "Limit states design of steel structures". Rexdale: Canadian Standards Association; 2001.

[5] EN 1994-1. "Design of composite steel and concrete structures, Part 1-1: General rules and rules for buildings". Brussels (Belgium): CEN, European Committee for Standardization; 2004.

[6] Hunaiti, Y. M., Fattah, B. A. "Design considerations of partially encased composite columns". Proc., Institute of Civil Engineers, Structures and Buildings, 106(2), pp. 75-82. 1994. https://doi.org/10.1680/ istbu.1994.25681

[7] Muise, J. "Behaviour of simple framing connections to partially concrete encased H section columns" Master's Thesis, Dept of civil engineering, University of Toronto, Toronto, Canada. 2000.

[8] Chicoine, T., Tremblay, R., Massicotte, B., Ricles, J., Lu, L. W. "Behaviour and strength of partially encased composite columns with built up shapes". Journal of Structural Engineering, 128(3), pp. 279-288. 2002. https://doi.org/10.1061/(ASCE)0733-9445(2002)128:3(279)

[9] Chicoine, T., Massicotte, B., Tremblay, R. "Finite element modelling and design of partially encased composite columns". Steel and Composite Structures, 2(3), pp. 171-194. 2002. https://doi.org/10.1061/(ASCE)0733.9445 (2002)128:3(279)

[10] Prickett, B. S., Driver, R. G. "Behaviour of partially encased composite columns made with high performance concrete". Structural engineering report No 262. Dept of civil and environmental engineering, University of Alberta, AB, Canada, 2006.

[11] Ebadi Jamkhaneh, M., Kafi, M. A. "Experimental investigation of octagonal partially encased composite columns subject to concentric and eccentric loading". Journal of Rehabilitation in Civil Engineering, 2017. https://doi.org/10.22075/JRCE.2017.12538.1216

[12] Ebadi Jamkhaneh, M., Kafi, M. A., Kheyroddin, A. "Experimental and numerical investigations of partially encased composite columns under axial load". Journal of Structural and Construction Engineering, (JSCE). (in persian) 2017. https://doi.org/10.22065/JSCE.2017.92721.1264

[13] Begum, M., Driver, R. G., Elwi, A. E. "Finite element modeling of partially encased composite columns using the dynamic explicit solution method". Journal of Structural Engineering, 133(3), pp. 326-34. 2007. https://doi.org/10.1061/(ASCE)0733-9445(2007)133:3(326)

[14] Begum, M., Driver, R. G., Elwi, A. E. "Behaviour of partially encased composite columns with high strength concrete". Engineering Structures, 56, pp. 1718-1727. 2013. https://doi.org/10.1016/j.engstruct.2013.07.040

[15] Chen, Y., Wang, T., Yang, J., Zhao, X. "Test and numerical simulation of partially encased composite columns subject to axial and cyclic horizontal loads". International Journal of Steel Structures, 10(4), pp. 385-93. 2010. https://doi.org/10.1007/BF03215846

[16] Pereira, F. M., De Nardin, S., El Debs, L. H. C. "Structural behaviour of partially encased composite columns under axial loads". Steel and Composite Structures, 20(6), pp. 1305-1322. 2016. https://doi.org/10.12989/ scs.2016.20.6.1305
[17] CSA S16-14. "Limit States Design of Steel Structures". Mississauga (Ontario): Canadian Standards Association; 2014.

[18] ACI 318R-08. "Building Code Requirements for Structural Concrete (ACI 318-08) and Commentary". Farmington Hills, MI: American Concrete Institute; 2008.

[19] ACI 363R-92. "State-of-the-art report on high-strength concrete (reapproved in 1997)". Farmington Hills, MI: American Concrete Institute; 1997.

[20] A370-03. "Standard test methods and definitions for mechanical testing of steel products". Philadelphia, PA: American Society for Testing and Materials; 2003.

[21] ABAQUS User's Manuals, Version 6.14.2. Rhode Island, Hibbitt, Karlsson and Sorensen Inc. USA. 2014.

[22] Gorst, N. J. S., Williamson, S. J., Pallet, P. F., Clark, L. A. "Friction in Temporary Works". Research Report 071, Health and Safety Executive, University of Birmingham, Birmingham, UK, 2003.

[23] Hillerborg, A., Modeer, M., Petersson, P. E. "Analysis of crack formation and crack growth in concrete by means of fracture mechanics and finite elements". Cement and Concrete Research, 6, pp. 773-782. 1976. https:// doi.org/10.1016/0008-8846(76)90007-7

[24] Coronado, C. A., Lopez, M. M. "Sensitivity analysis of reinforced concrete beams strengthened with FRP laminates". Cement and Concrete Composites, 28(1), pp. 102-114. 2006. https://doi.org/10.1016/j.cemconcomp. 2005.07.005

[25] CEB-FIP. "Final draft CEB-FIP model code". 1990. Bulletin Information Committee Euro-International, Beton 203. 1990.

[26] Rots, J. G. "Computational Modeling of Concrete Fracture". Ph.D. thesis, Delft University of Technology, Delft, Netherlands, 1988.

[27] Hsu, L.S., Hsu, C.T.T. "Complete stress-strain behaviour of high-strength concrete under compression". Magazine of Concrete Research, 46(169), pp. 301-312. 1994. https://doi.org/10.1680/macr.1994.46.169.301

[28] Nayal, R., Rasheed, H. A. "Tension stiffening model for concrete beams reinforced with steel and FRP bars". Journal of Materials in Civil Engineering, 18(6), pp. 831-841. 2006. https://doi.org/10.1061/(ASCE)08991561(2006)18:6(831) 